\title{
Genetic information and testing in insurance and employment: technical, social and ethical issues
}

\author{
On behalf of the European Society of Human Genetics' PPPC
}

European Journal of Human Genetics (2003) 11, 909-910. doi:10.1038/sj.ejhg.5201104

Published online 22 October 2003

\section{Introductory considerations}

One of the more complex policy issues accompanying developments in genetic knowledge relates to how personal genetic information, such as the results of genetic tests, are to be used. To discuss these issues as they relate to insurance and employment and produce recommendations from the professional point of view, the Public and Professional Policy Committee $\left(\mathrm{PPPC}^{\star}\right)$ of the European Society of Human Genetics (ESHG) organized a workshop** in February, 2000 in Manchester (UK) to which 47 experts from 14 European countries were invited. They received, prior to the meeting, a working paper developed by the PPPC, which was revised after the meeting to take into account the points of view expressed by the participants. Following the workshop, the ESHG issued statements and recommendations that are expected to reflect the views of the scientific community and that were endorsed by the ESHG membership.

\section{Statements and recommendations Genetic information and insurance Defining the framework}

(1) Basic insurance is an essential element of social structure. The definition of what constitutes 'basic needs' should be subject to policy discussions, and must be a matter of social and political negotiation within each country. The mechanisms for supplying this basic level of cover and its provision through state or commercial insurance, is also a matter for individual countries to negotiate, but should not depend on the individual's genetic make up. A solidarity component within commercial insurance can be provided through the system of a threshold level of insurance cover, below which genetic information need not be disclosed. In such a system, clients generate an element of solidarity in covering existing or future genetic disadvantage by all paying the same premium. Where such a threshold exists, the reasons for choosing the threshold value should be given.

(2) Clear definitions of terms used in genetics, insurance and employment should be developed, so that different professions and their clients have a common understanding of the issues. In these recommendations, the term genetic information (of which genetic test results are a part) refers to:

- information that derives directly from the variation between people who exist in their chromosomes or DNA, or

- information that is being used to infer that a specific genetic variation or genetic influences might be present.

The former includes cytogenetic and DNA test results and very specific biochemical changes, while the latter category of genetic information includes family history, clinical diagnosis, imaging, clinical chemistry test results, etc.

Declaring the grounds on which genetic information is or is not used

(3) There must be a detailed and transparent process by which the relevant evidence is assessed and translated into actuarial risks before genetic information is incorporated into insurance decisions. To develop a practice fair to both insured and insurer requires:

(a) That any use of genetic information to predict risk of disease or death in insurance must be able to withstand independent scientific scrutiny.

(b) Agreement between insurance and health-care professionals on the best means for determining the extent of increased genetic risk of late-onset disease, so that there is demonstrable evidence of validity and consistency in the use of genetic information in underwriting.

(4) If an insurance contract requires disclosure of genetic information, this should relate only to genetic information that is relevant to that insurance policy. It follows that the insurers should specify precisely what genetic information is relevant and why, and how it will be used.

(5) It is difficult to predict the extent to which genetic tests might become relevant for health prediction in 
complex diseases, and even more difficult to predict the extent of the influence and timing of such advances in knowledge. Sound knowledge of the real predictive value of the information must be validated before such tests are put into both clinical and insurance practice.

Promoting confidence between the public and the insurance industry

(6) Applicants should not be asked to undergo genetic tests in order to obtain insurance.

(7) The nature and presentation of insurance policies should not unduly influence the decisions of individual clients on whether or not to undertake genetic tests for clinical purposes.

(8) The confidentiality of all clinical information, including genetic information, is absolute. Genetic information that is obtained for an insurance policy can only be used for that client and no other. Fresh information must be obtained if other family members apply for insurance, based on what that family member has been informed. Procedures must ensure that there is no internal transfer of such genetic information within the industry.

(9) There is a need for sound actuarial research in this area to allow insurance practice to develop an evidence base. Insurance decisions should not be based on unvalidated extrapolations from clinical research data gathered from selected case series.

(10) There is a need for ongoing research into the experiences of people with an existing or potential genetic disadvantage when seeking to use insurance, so that the social and economic impact of different approaches and policies can be known and compared.

(11) Consumer and commercial confidence in the validity of the use of genetic information in underwriting will be best maintained by the use of an independent review system.

\section{Genetic information and employment}

(1) There is currently very little use of genetic information in relation to employment, but the situation should be kept under review.

(2) It is not usually acceptable for people to be excluded from particular types or areas of employment, or advancement, because of genetic information. These decisions should be based on an individual's current ability to do a specific job and their current health status in so far as this is relevant to the job.

(3) Situations where the safety of clients or members of the public is put at risk are an exception to statement 2 .

(4) Where genetic testing could in principle protect an employee from a specific work-related hazard, such tests should be available to the employee on a voluntary basis with informed consent.

(5) Where a valid case is made for employment-related genetic testing, a new regulatory model should be explored, in which employment-related tests are provided and supervised by an independent agency, rather than the individual employer. The tests should be voluntary, directed at specific hazards (eg radiation, dust, chemicals) to be specified by the agency and not the employer. The test results from the agency would be made available only to the employee directly.

This document forms part of a BIOTECH programme financed by the Commission of the European Communities (CEE BIO4-CT98-0550).

All rights reserved. No part of this document may be reproduced or utilized in any form or by any means, electronic or mechanical, including photocopying, recording, microcopying, or by any information storage and retrieval system, without permission in writing from the copyright holder.

CCopyright 2000 by ESHG/PPPC (Nov 2000)

*Members of the PPPC were: Ségolène Aymé (Paris, France), Martin Bobrow (Cambridge, UK), Gerry EversKiebooms (Leuven, Belgium), Peter Farndon (Birmingham, UK), Helena Kääriäinen (Helsinki, Finland), Ulf Kristoffersson (Lund, Sweden), Marcus Pembrey (London, UK), Sandy Raeburn (Nottingham, UK) Albert Schinzel (Zürich, Switzerland), Jörg Schmidtke (Hannover, Germany), Leo ten Kate (Amsterdam, Netherlands), Lisbeth Tranebjaerg (Copenhagen, Denmark).

**The workshop was organized by: Martin Bobrow (Cambridge, UK), Peter Farndon (Birmingham, UK), Marcus Pembrey (London, UK) and Sandy Raeburn (Nottingham, UK).

Correspondence: Professor S Ayme Hôpital Broussais, INSERM SC 11, 102 rue Didot, Paris F-75014, France.

Tel: + 3315653 8137; Fax: + 3315653 8138; E-mail: ayme@orpha.net 